\title{
O ACOPLAMENTO ENTRE SOCIEDADE E ECONOMIA: A TEORIA DOS SISTEMAS NAS CONTRIBUIÇÕES DE TALCOTT PARSONS E NIKLAS LUHMANN
}

\author{
THE COUPLING BETWEEN THE ECONOMY AND SOCIETY: \\ THE THEORY OF SYSTEMS IN THE CONTRIBUTIONS \\ OF TALCOTT PARSONS AND NIKLAS LUHMANN
}

\section{Fabrício Monteiro Neves ${ }^{1}$ \\ Hélio Afonso de Aguilar Filho ${ }^{2}$}

\begin{abstract}
RESUMO: Mais recentemente, a preocupação comum de sociólogos e economistas com temas que pareciam ser antes exclusivos à sociologia e à economia tem suscitado importantes reflexões sobre as possibilidades da cooperação interdisciplinar. Contribuições dos dois lados têm sido relevantes nesse sentido. Na economia, assiste-se ao resgate do institucionalismo, que, mesmo sobre novas roupagens, tem dado um caráter mais social às pesquisas econômicas. Na sociologia, o surgimento de uma disciplina específica, a Nova Sociologia Econômica, também caminha reforçando a preocupação com o caráter social dos fenômenos econômicos. $\mathrm{O}$ presente trabalho, à luz dessas preocupações, discute o imbricamento social da esfera econômica. A ênfase, contudo, é na Teoria dos Sistemas de Talcott Parsons e Niklas Luhmann, pelo entendimento de que esta, principalmente na perspectiva do segundo autor, pode apresentar contribuições tanto do ponto de vista formal quanto substantivo para aproximar o domínio econômico do social.
\end{abstract}

Palavras-chaves: Imbricamento; Teoria dos Sistemas; Nova Sociologia Econômica; Talcott Parsons; Niklas Luhmann.

[1] Doutor em Sociologia, professor adjunto do Departamento de Sociologia da Universidade de Brasília - UnB, DF, Brasil, e-mail: fabriciomneves@gmail.com

[2] Doutor em Desenvolvimento Econômico, professor adjunto do Departamento de Economia da Universidade Federal do Rio Grande do Sul - UFRGS, Porto Alegre, Brasil, e-mail: haaf73@yahoo.com.br 
ABSTRACT: More recently, the common concern of economists and sociologists with themes that seemed to be exclusive before the sociology and economics, has raised important points about the possibilities of interdisciplinary cooperation. Contributions from both sides have been leading in this direction. The economy is experiencing the rescue of institutionalism, that even on new robes, has a more social character of economic research. In sociology, the emergence of a specific discipline, the New Economic Sociology, also walks reinforcing the concern with the social character of economic phenomena. This work, in the light of these concerns and others, discusses the overlapping of social economic sphere. The emphasis, however, is the Systems Theory of Talcott Parsons and Niklas Luhmann. This we understand by the prospect of systems offered by these authors, especially the second, may make contributions in both formal substantive to bring about the economic domain of society.

Key-words: Embeddedness; Systems Theory; New Economic Sociology; Talcott Parsons; Niklas Luhmann.

\section{INTRODUÇÃO}

A economia figurou, muito cedo, como um ramo bem definido dentro das Ciências Sociais. A separação daquilo que seria o comportamento econômico em relação às demais motivações estudadas, por exemplo, pela sociologia e pela política, ganhou um domínio específico, com qualificações e respaldos tanto em justificativas substantivas quanto formais. Isto é, do ponto de vista substantivo, coube à economia, como a todas as outras ciências, delimitar seu objeto, que foi definido a partir do estudo dos fenômenos relacionados com a alocação eficiente de recursos escassos. Do ponto de vista formal, a criação das disciplinas acadêmicas e a divisão do trabalho entre áreas do saber mostrar-se-iam, segundo seus defensores, mais 
promissoras para a produção e acúmulo de conhecimento do que a sua contraparte, a contribuição interdisciplinar.

Mais recentemente, as tradicionais fronteiras alicerçadas entre os ramos das ciências sociais vêm sendo gradualmente solapadas, o que pode ser comprovado pela maior preocupação dos economistas em estudar tópicos antes tradicionalmente estudados por sociólogos, e pelos sociólogos estudando temas até então exclusivos da economia. A Nova Sociologia Econômica, a partir do seminal trabalho de Mark Granovetter, Economic Action in Social Structure: a theory of embeddedness, de 1985, tem surgido, nesse contexto, como um campo do conhecimento que visa a resgatar a economia do seu confinamento mediante a sua articulação com o social.

No que diz respeito ao resgate feito pela Nova Sociologia Econômica, a crítica acusa dois erros. O primeiro, do ponto de vista substantivo, é que, se a definição de ator racional da economia subsocializa o comportamento humano, é comum, aos autores da Nova Sociologia Econômica, sobressocializar os indivíduos dentro das estruturas sociais. Isto é, passa-se do homo economicus neoclássico para o homo sociologicus, cujo comportamento é inteiramente determinado pelas instituições sociais. A segunda crítica, partindo de critérios formais, enfatiza que os trabalhos da Nova Sociologia Econômica não chegariam a representar um programa de pesquisa, ou seja, faltar-lhes-ia um núcleo analítico coerentemente delimitado e articulado, que apresentasse viabilidade intrínseca em termos de pesquisa. Em consequência, muitas das suas formulações, além de figurarem de forma imprecisa e pouco consistente, ainda seriam circulares e ambivalentes.

O presente trabalho, na tentativa de lançar luz sobre a compreensão dos fenômenos econômicos e sua inter-relação com os demais fenômenos sociais, aborda a perspectiva da Teoria dos Sistemas particularmente em dois autores: Talcott Parsons e Niklas Luhmann. A perspectiva de Parsons é importante porque esse autor é um dos iniciadores da Teoria dos Sistemas na sociologia, ademais, Parsons é, muitas vezes, acusado de ter sancionado definitivamente a divisão 
do trabalho entre economistas e sociólogos. Luhmann, por sua vez, é um autor pouco lido e trabalhado, inclusive na sociologia, mas sua obra representa contribuições mais definitivas, bem como um maior refinamento dessa teoria.

A principal justificativa para o presente trabalho é que a redução analítica de complexidade trazida pela "Primeira Batalha dos Métodos", com sua separação entre conhecimento histórico e conhecimento teórico, já apresenta sinais de esgotamento em termos de contribuição às Ciências Sociais. Uma nova forma de organizar e compreender os fenômenos econômicos e a sua relação com o social faz-se, assim, cada vez mais necessária. Essa compreensão, por um lado, exige uma estrutura teórica que está muito além das possibilidades oferecidas pelo instrumental da Nova Sociologia Econômica; por outro lado, exige que o domínio do "social" seja visto numa perspectiva mais ampla, com finalidade e natureza distintas daquelas encontradas na esfera econômica, e cuja influência condiciona o funcionamento e a evolução histórica desta esfera. Ao mesmo tempo, esse domínio não deve simplesmente se sobrepor ao econômico, como é comumente feito pela sociologia tradicional. Por isso, o ideal seria uma teoria que procurasse preservar a inter-relação entre as diversas esferas da sociedade (do social, do econômico e do político), possibilitando também unir, numa mesma perspectiva, o papel da interação social e da estrutura social e o papel do interesse.

O presente trabalho está dividido assim como segue. Além desta introdução, conta com uma segunda seção em que será abordada a relação da economia com o social. Na terceira seção, discute-se a contribuição de Parsons para a teoria dos sistemas. Na quarta seção, apresenta-se a visão de Luhmann, bem como a sua contribuição para a Teoria dos Sistemas e para a questão da separação entre as esferas sociais. Por último, na quinta seção, conclui-se o trabalho. 


\section{O SALTO QUALITATIVO: DA TEORIA ECONÔMI- CA NEOCLÁSSICA AO NOVO INSTITUCIONALISMO}

A economia despontou logo cedo como o ramo das Ciências Sociais que mais aproximadamente atendia as exigências metodológicas impostas pela comunidade acadêmica para a demarcação do conhecimento científico. Isso pelas características próprias do seu método, com acentuado conteúdo formal e dedutivo, bem característicos da física clássica e a gosto das teorias prescritas dos séculos XIX e início do século XX.

O princípio que permitiu à economia desfrutar do seu privilegiado status teórico foi a concepção de que toda ação econômica "tem suas raizes numa propriedade fundamental da natureza humana, na luta do homem pela maior soma de felicidade que possa atingir" (Kaufmann, 1977, p.251). Preferindo o agente econômico, em consequência, uma porção maior de riqueza a uma menor. Esse princípio nasceu com Adam Smith, foi sistematizado por J. B. Say e sofreu os refinamentos de David Ricardo. Não que esses autores não concebessem a existência de outras motivações para o comportamento humano, mas, em se tratando dos fenômenos de mercado propriamente ditos, interessaria saber como agiria um homem cujo propósito seria o de aumentar a riqueza o mais possível, da maneira mais adequada.

Às contribuições iniciais, o que se seguiu na economia, então, foi a consolidação do programa de pesquisa neoclássico. A economia, além do utilitarismo e do marginalismo, seguia de perto a definição de Robbins (1999, p.12), estudava "o comportamento humano como uma relação entre fins e meios escassos com usos alternativos". A consolidação do núcleo de pesquisa neoclássico dependeu dos esforços conscientes de Marshall, que buscou "a continuidade com a teoria clássica, incorporando o marginalismo ao corpo principal da economia, mas também o integrou com teorias clássicas de renda e de comércio internacional" (Desai, 1996, p.228). 
Com a teoria neoclássica, a opção deliberada pela sustentação de um individualismo metodológico restrito, além das hipóteses adicionais de comportamento maximizador, de equilíbrio de mercado e de estabilidade das preferências, fez com que a ciência econômica figurasse, cada vez mais, como um ramo autônomo do conhecimento (Abramovay, 2004). Cabe ressaltar, porém, que os teóricos neoclássicos não se negaram a reconhecer a importância da dimensão histórica e social para o entendimento dos fenômenos econômicos propriamente ditos. A razão pela qual dedicaram tão pouca atenção ao estudo da evolução institucional se deve antes ao corte metodológico ao qual se vincularam, assumindo que as instituições emergem espontaneamente do comportamento racional dos agentes, que as criam com a finalidade exclusiva de maximizar seu bem-estar e que, por conseguinte, também podem aperfeiçoá-las a qualquer tempo, através do processo de realimentação de informações obtidas no mercado.

A sociologia, por sua vez, segundo Parsons (apud, Velthuis, 1999, p.630), sancionou a divisão do trabalho entre economistas e sociólogos, estabelecendo, como seu domínio, o tratamento dos fenômenos relacionados com os "valores, com os fins comuns e as atitudes associadas consideradas em seus vários modos de expressão na vida social humana". Derivaram-se, dessa divisão, a legitimação do programa de pesquisa neoclássico e a negligência aos trabalhos dos economistas institucionalistas e da sociologia econômica durante boa parte do século XX.

A partir da década de 1970, seguindo a crise de consenso que se debruçou sobre a chamada síntese neoclássica, os economistas procuraram revisar metodologicamente os alicerces da sua ciência. Nesse sentido, ocorre um gradual questionamento das tradicionais fronteiras que separam as ciências sociais. Pode-se ver, por exemplo, economistas como Gary Becker e Oliver Williamson estudando tópicos tradicionais da sociologia, e sociólogos como Harrison White a Mark Granovetter estudando tópicos tradicionais da economia (Swedberg, 1990). O que pode estar acontecendo, na visão de Swedberg 
(1990), é uma Nova Batalha dos Métodos. Enquanto a primeira teria dado os passos iniciais para marcar a separação da teoria econômica em relação à história e à sociologia; a segunda pode muito bem estar levando ao fim das tradicionais formas de análise das ciências sociais. A prova é que a economia parece estar caminhando numa direção contrária à sugerida pela teoria do equilíbrio geral walrasiano. A ideia de que as relações econômicas consistem num conjunto atomizado de sujeitos egoístas interagindo ocasionalmente com base num mecanismo automático e tendente ao equilíbrio não é mais unanimidade na disciplina. Outro ponto a se destacar é com relação a grande virada cognitiva, ou seja, o destacado papel conferido à incerteza e às limitações na capacidade racional do ser humano, além da adoção de modelos mentais partilhados pelos atores (Abramovay, 2004).

\subsection{O Novo Institucionalismo (NEI)}

O novo institucionalismo (NEI), pelo menos na versão de Oliver Williamson e Douglass North, é uma mostra do quão a economia tem caminhado em busca de novos padrões de interação e da sua influência sobre o comportamento econômico. Assim, ao destacar a existência de custos de transação, Williamson está reconhecendo que a interação social não é fluida nem automática, abrindo caminho para a comunicação com a sociologia. North vai além, reconhecendo a importância dos sistemas de crenças subjacentes a determinadas sociedades em promover o crescimento econômico.

A atribuição pela NEI de uma dimensão mais institucional aos estudos da economia, entretanto, não tem ocorrido imune à crítica. De acordo com Guedez (2000) e Hodgson (1988, 1993), os Novos Institucionalistas fazem do individualismo metodológico seu ponto de partida para a análise dos fenômenos sociais, passando a propor um diálogo com a economia mainstream a partir da constatação de que as instituições importam quando se trata de entender as falhas de mercado. Ainda segundo Hodgson, o comportamento individual é tomado pela NEI, tanto quanto pela teoria neoclássica, como sendo 
exógenos às instituições e organizações. A linha descrita por Hodgson (1988) para demarcar o neoclassicismo no institucionalismo é traçada a partir da proposição comum ao liberalismo econômico, ou seja, a visão de que os indivíduos e as suas preferências podem, em certo sentido, ser concebidos como o ponto de partida da análise. Assim, na agenda de pesquisa da NEI, consta como proposição principal, segundo Hodgson (1988, 1993), a questão da emergência das instituições e sua eficiência comparativa. A partir desse ponto, os autores afiliados a essa escola buscam explicar a existência da política, da ordem legal ou, mais amplamente, das instituições sociais, tendo como referência o modelo de comportamento individual.

Ademais, ao tomar o 'indivíduo' como ponto de partida, a NEI estaria tentando explicar a emergência, a existência e o desempenho das instituições sociais em termos de interação entre indivíduos 'dados'. Concebe-se, nesse caso, a possibilidade das instituições afetarem o comportamento individual, mas somente em termos de escolhas e restrições presentes para os agentes, não na moldagem das preferências e da própria individualidade desses agentes. Em outras palavras, dentro de tal lógica, as instituições emergem com base no comportamento individual, a sua função é a de prover as restrições externas, as convenções ou oferecer, para os indivíduos, o que deve ser 'dado'. Por fim, a possibilidade de que os indivíduos sejam moldados em sua interação com as instituições não é considerada.

\subsection{A Nova Sociologia Econômica}

No caso da Nova Sociologia Econômica, o seu surgimento vem como um contraponto ao interesse recente da economia acadêmica pela dimensão social da ação econômica. Em suas várias vertentes, os seus membros reconhecem os avanços da nova economia institucional em relação à teoria neoclássica, mas criticam o artificialismo da inserção do social pelo econômico feita pelos adeptos da NEI. Granovetter, por exemplo, chama a atenção para a subsocialização do agente econômico no pensamento de Williamson, em que 
a interação entre as pessoas é entendida de um ponto de vista quase ocasional, desconsiderando-se as estruturas de enquadramento. Por outro lado, a Nova Sociologia Econômica ressalta o caráter social do mercado, visto como espaços reais de confronto entre atores, cuja forma depende da força, da organização, do poder dos recursos de que dispõe cada parte.

Um reconhecimento importante no entendimento do mercado e das ações econômicas como sendo resultantes concretas da interação social, advém do conceito de embeddedness, de Karl Polanyi. $\mathrm{O}$ seu resgate foi feito por Mark Granovetter nos anos 80, justamente com a finalidade de mostrar o conteúdo social da análise dos fenômenos econômicos. A partir de então, o termo embeddedness tem sido usado pelas diversas áreas da sociologia econômica com diferentes objetivos ${ }^{1}$. O uso mais comum a que se prestado, entretanto, tem sido no sentido de resgatar a economia ortodoxa de seu confinamento mediante sua articulação com o resto das ciências sociais e a incorporação discreta de algumas variáveis de índole não econômica (Gómez Fonseca, 2004).

A ênfase da Nova Sociologia Econômica na questão da socialização do homem também não está imune a críticas. Se, por um lado, a economia e a NEI subsocializam a ação humana, Swedberg (2005) e Boettke; Storr (2002) apontam o equívoco mais comum entre os autores da Nova Sociologia Econômica, ou seja, o de sobressocializar o comportamento humano dentro das estruturas sociais. Nesse último caso, as instituições são, muitas vezes, vistas como o principal condicionante do comportamento humano.

Sobre a Nova Sociologia Econômica, a conclusão é que a mesma tem contribuído, sem dúvida, para estreitar as distâncias entre a perspectiva econômica e a sociológica, principalmente por sua atitude de desrespeito e irreverência para com a economia acadêmi-

[1] Os quatro exemplos a seguir, dentre muitos outros, mostram alguns desses usos. Primeiro, para explicar as imigrações para os Estados Unidos. Segundo, para estudar as mudanças sociais e no curso de vida. Em terceiro, para analisar os movimentos de redes sociais. E o quarto, para estudos sobre a emergência da sociedade civil na historia hispânica recente (BARBER, 1995). 
ca tradicional. Apesar disso, esses trabalhos não chegam, segundo a crítica, a representar um programa de pesquisa, ou seja, falta-lhes um núcleo analítico coerentemente delimitado e articulado, que apresente viabilidade intrínseca em termos de pesquisa. Em consequência, como atesta Carlos Graça (2004), muitas das suas formulações além de figurarem de forma imprecisa e pouco consistente - sua única força representa não mais que ser um meio termo entre as formulações da economia e as da sociologia - pecam pela ambivalência e pela circularidade.

\section{A TEORIA DOS SISTEMAS: UMA SÍNTESE ECO- NOMIA-SOCIOLOGIA?}

A sociologia moderna colecionou uma série de contradições em sua história, dado que sua agenda inicial - pensar a ordem social - já apresentava, em seu núcleo, potenciais problemas a se resolver. O primeiro era a herança do liberalismo clássico, que trazia o indivíduo para o centro da análise, e considerava tal categoria o núcleo fundante de todo o processo social. Para esse grupo de sociólogos, cabia compreender o motivo subjacente à ação, o sentido vinculado pelos próprios indivíduos ao seu comportamento. Posteriormente, surgiram análises baseadas em estruturas coercitivas, como a cultura, deslocando o indivíduo do centro das preocupações sociológicas, fazendo emergir um objeto específico de análise, a sociedade, que estaria em posição diferente e, às vezes, oposta a do indivíduo. Isso vai, portanto, bifurcar a sociologia, permitindo que seu período clássico seja dividido entre os teóricos da ação e os teóricos da estrutura, e, mais contemporaneamente, entre os teóricos da micro e da macro teorização. Essa é a problemática que chega a Talcott Parsons na década de 30 e que encontrará um refinamento teórico na abordagem mais contemporânea de Niklas Luhmann. Ambas as abordagens se propuseram um desafio, a saber, a síntese dessas posições aparentemente contraditórias. 


\section{1 - A teoria dos sistemas em Talcott Parsons e a economia.}

Parsons foi o formulador da proposta teórica conhecida como estrutural-funcionalismo, uma vertente sociológica americana que se tornou dominante em boa parte do século passado, legando frutos até hoje. Seu pioneiro trabalho, The sctructure of social action (1937), foi uma revisão crítica de uma geração anterior de sociólogos europeus, cujos trabalhos se apresentavam ao autor como empreendimentos teóricos convergentes. Tais autores - Weber, Durkheim, Marshall e Pareto - buscavam saídas ao individualismo utilitarista, o qual fora também alvo das críticas de Parsons 1 . A síntese de Parsons dos autores acima não trata de um agrupamento de conceitos, pelo contrário, busca a sistematização de uma teoria empiricamente baseada, a chamada Teoria Voluntarista da Ação (Parsons, 1937, p. 12). Tal teoria articularia a discussão da ordem social em Durkheim com as investigações Weberianas em torno da ação social, ou seja, era uma síntese de propostas aparentemente irreconciliáveis, uma teoria estrutural e uma teoria individualista. Para tanto, utiliza a unidade de análise "sistema social"

Como ficará mais evidente em obras posteriores, para Parsons, "ação é sistema", e os sistemas sociais são definidos como "constituído pela interação direta ou indireta dos seres humanos entre si” (1976, p. 49). O que Parsons queria era uma teoria da sociedade e, para isso, era necessária a síntese ação-estrutura. Surge, nessa concepção, o problema da dupla contingência da ação, ou seja, o fato de que, na interação, as possibilidades de ação de EGO e ALTER são contingentes - pelo lado de EGO e pelo lado da reação de ALTER - produzindo, no limite, uma impossibilidade de comunicação, o que levaria concomitantemente à impossibilidade de reprodução da sociedade. Esse fenômeno, que se nos apresenta de forma objetiva, pressupõe, para a sua superação, um sistema simbólico compartilhado, que faz com que a reação de ALTER “adquira para EGO o

[1] Já na introdução da obra, há uma ácida crítica a Herbert Spencer, um dos expoentes de tal concepção.

[2] A discussão dos sistemas sociais será feita em obra posterior, The Social System (1951). 
significado de uma consequência apropriada da conformidade ou desvio de EGO das normas de um sistema simbólico compartilhado" (Parsons; Shils, 1951, p. 16).

Deve-se, no sentido acima, integrar teoricamente a ação em sistemas gerais específicos para entender seu curso, e, para isso, Parsons cria um modelo em tabelas cruzadas que orientam o esquema fim/meio da ação social. No eixo horizontal, estarão aqueles componentes relacionados à ação: i) instrumental - o meio que leva a atuar - e ii) consumatória - o fim, a satisfação adquirida e o aperfeiçoamento do sistema. No eixo vertical, estarão os componentes do sistema que se relacionam com o exterior ou com as suas próprias estruturas. Esses sistemas gerais de ação eram definidos com relação à interação concreta e estudados por meio do esquema AGIL, isto é, as quatro funções que todo sistema deveria apresentar para existir e que surgem em função das combinações possíveis. São elas: adaptação (Adaptation), realização de metas (Goal-attainment), integração (Integration) e manutenção de padrões latentes (Latency). Cada função caracterizaria sistemas particulares "por processos e estruturas com elas relacionados, assim como por meios gerais que controlam tais processos" (Münch, 1999, p. 184).

Tabela 1 - Sistema geral da ação.

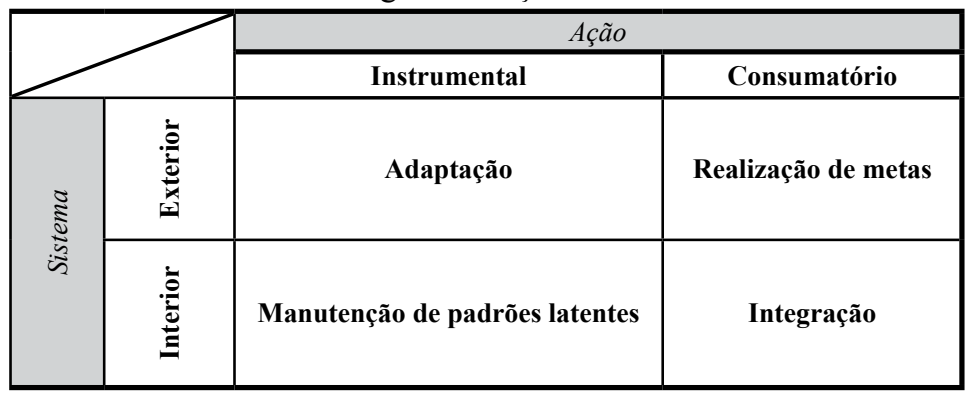

Adaptado de Luhmann, 1996.

Com esse modelo, podem-se observar vários sistemas e subsistemas coexistindo na realidade. Por exemplo, no nível mais abstrato da condição humana, o sistema físico-químico é controlado por 
meio da ordem empírica e é responsável pela adaptação; o sistema orgânico se encarrega dos fins especificados, que são controlados pela saúde do organismo; o sistema télico, por sua vez, encarrega-se das condições transcendentais da existência; e, finalmente, o sistema geral da ação, que é controlado pelos limites semânticos e é responsável pela integração. Esse último é aquele do qual a sociologia se ocupa, e, nele, Parsons imprime o mesmo esquema analítico, subdividindo-o em quatro subsistemas: os sistemas sociais, os sistemas culturais, os sistemas de personalidade e os organismos comportamentais. Ao sistema social, cabe a integração; ao sistema cultural, a manutenção de padrões latentes; aos sistemas de personalidades, a realização de metas; e, finalmente, aos organismos comportamentais, a adaptação (Parsons, 1974). A tabela abaixo apresenta o esquema em termos dos sistemas sociais.

Tabela 2 - Sistema social geral

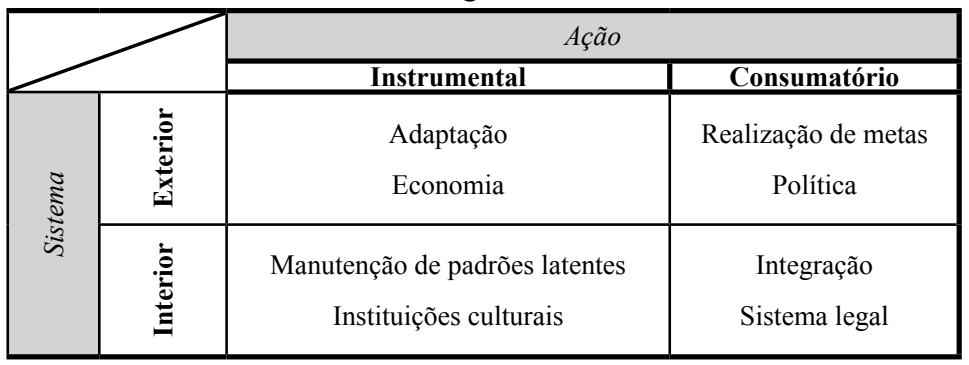

Adaptado de Luhmann, 1996.

Importa, para o presente trabalho, a combinação entre instrumental e exterior, que cria o componente adaptação, processo em que os elementos exteriores ao sistema são instrumentalizados para a satisfação de determinadas necessidades. Cabe à economia tal processo para a reprodução da sociedade em todas as suas dimensões. Como sistema social, a economia, da mesma forma, necessita também completar as variáveis relativas à ação, quer dizer, "repetir dentro de si mesmo as possibilidades de combinação das quatro células gerais: adaptation - goal attainment - latent pattern main- 
tenance - integration" (Luhmann, 1996, p. 36). Esse processo faz com que surja a história como diferença no tempo da realização, no sistema, das quatro funções necessárias à sua reprodução. Portanto, em momentos específicos, cada sistema completa as exigências de reprodução de modo diferente, tal como indicado, por exemplo, pela função de integração. Sem esta, haverá descompasso na reprodução das funções requeridas, já que é tal função que regula os intercâmbios simbólicos entre os sistemas. Eles são integrados, em grande parte, por meios simbólicos característicos, como o dinheiro, no que diz respeito à economia; e o poder, relativo à política.

Parsons avança na noção de intercâmbios, entendendo-o a partir do conceito de interpenetração, ou a "interiorização de objetos sociais e normas culturais pela personalidade do individuo" (Parsons, 1974, p. 17). Ou seja, a personalidade interioriza as normas culturais, e, em decorrência, para o sistema de ação geral, isso representaria a manutenção do padrão cultural e disporia as metas em seus próprios termos. Nota-se aqui, claramente, uma visão de sistema caracteristicamente aberto em virtude das "zonas de interpenetração", que possibilitam intercâmbio simbólico entre sistemas. Em decorrência dessa concepção, Parsons desenvolve uma ideia de ordem ligada ao conceito de equilíbrio e integração, muito utilizada pela teoria dos sistemas em sua época. Isso leva a dizer que mudanças nas condições externas de dado sistema social funcionam como um fator exógeno de mudança interna (Sorokin, 1969, p. 400). Nesse sentido, a cultura interiorizada importa para a reprodução econômica de dada sociedade. Essa arquitetura teórica, portanto, vai desenvolver uma teoria da integração social baseada nas relações entre sistemas sociais. Como afirma Parsons (1951, p. 42): "Esta integração de um conjunto de padrões valorativos comuns com a estrutura de disposições necessárias das personalidades constituintes é o fenômeno principal das dinâmicas dos sistemas sociais". Ou seja, padrões de valores comuns estão presentes na ação social, quaisquer que sejam eles, e, por isso, a "teoria econômica e outras versões de esquemas conceituais que dão proeminência a orientação baseada 
na razão instrumental não pode prover um adequado modelo para a análise dinâmica do sistema social em termos gerais" (Parsons, 1951, p. 42). Finalmente, com essa estrutura teórica, motivação tem a ver com valores que os indivíduos internalizam e dispõem na situação da ação, inclusive na ação econômica.

No que diz respeito à concepção geral de Parsons quanto a relação entre sociologia e economia, há ainda muita controvérsia entre seus intérpretes. A questão é que se sugeriu, durante grande parte do século passado, que, para Parsons, haveria uma divisão do trabalho entre sociologia e economia ${ }^{1}$, cabendo à primeira o estudo das ações não lógicas, e à segunda o estudo das ações lógico-racionais (Dalziel; Higgins, 2006). O problema que decorre dessa compreensão tem relação com os apontamentos teóricos acima: os sistemas se interpenetram, e a integração entre eles é fundamental para a reprodução social como um todo. Nesse sentido, tratar a sociedade e a economia como objetos isolados é uma forma de simplificar tal arcabouço teórico, já que, em toda a sua carreira, Parsons se aproximou ininterruptamente de uma concepção holístico-sistêmica do fenômeno social, com um modelo de observação baseado na diferença entre a parte e o todo. "Em termos sistêmicos, ele descreve a economia constituindo um subsistema da sociedade mais ampla, ou sistema social total, diferenciada em seus outros subsistemas como a política, cultura e comunidade societal" (Zafirovski, 2006, p. 79). Os meios simbólicos, como dito acima, interpenetram-se formando áreas comuns de relacionamentos como, por exemplo, entre dinheiro e poder, dinheiro e solidariedade, dinheiro e respeito, e assim por diante. Aí está a chave para se entender a relação entre economia e sociedade na teoria Parsoniana. Os subsistemas são interdependentes, e há intercâmbio simbólico entre as áreas de intercessão, decorrendo que o equilíbrio, em qualquer subsistema, é consequência do equilíbrio societal, o que implica que o equilíbrio econômico seja

[1] Claramente, tal separação foi assumida a partir de suas interpretações de Weber e Pareto. Ver Parsons, 1966. 
considerado uma parte do equilíbrio do todo, portanto, um fenômeno exogenamente condicionado.

\section{2 - O giro luhmanniano na teoria dos sistemas: há uma lógica intrínseca à economia?}

Niklas Luhmann desenvolveu uma teoria dos sistemas em um período em que pôde acompanhar novos êxitos teóricos advindos de várias áreas de investigação, como a cibernética e a biologia. Dessa última, um conceito para compreender a fenomenologia da célula promove uma inversão radical em sua perspectiva teórica, levando sua teoria da sociedade em direções diferentes que a de Parsons ${ }^{1}$. O conceito "autopoiésis", dos biólogos chilenos Humberto Maturana e Francisco Varela, busca explicar a reprodução celular, concebendo tal processo como a capacidade de cada unidade celular se reproduzir, baseando-se em seus próprios processos constituintes ${ }^{2}$. Não há intervenção desde fora, mas causalidade canalizada. Os sistemas, nesse sentido, deixam de ser abertos ao ambiente e são concebidos como sistemas fechados.

Para se compreender a teoria de Luhmann, deve-se investigar a forma como ele articula o conceito de sistema fechado com um conceito de sociedade. Essa forma definirá a posição do observador, a relação sistema/entorno e os distintos processos de diferenciação que compreendem os vários sistemas sociais que emergiram na sociedade. Essa abordagem traz consequências para as concepções a respeito do observador e da sua relação com o objeto, problematiza uma discussão epistemológica fundamental enraizada na concepção racionalista, a saber, a tradicional concepção que separa o sujeito do objeto. Tal concepção, ponto arquimédico da epistemologia até início do século passado, perde relevância diante da ideia de que o

[1] Luhmann fora aluno de Parsons na década de 1960, em Harvard, e esse encontro legou-lhe o interesse pela teoria geral da sociedade.

[2] Os intercâmbios entre célula e ambiente existem em função da direcionalidade que a célula impõe ao processo, o que faz com que a célula experimente seu ambiente baseando-se em si mesma, ela o reconstrói em seu interior de acordo com seus próprios processos constituintes. 
"observado", ao ser um construto de um observador - ou seja, ao ser diferenciado como entorno a partir dos critérios de um sistema específico -, é parte da própria “observação”. Portanto, não existiria "uma diferença constitutiva (desde a referência geral do sistema) entre sujeito e objeto, já que os dois participam de uma base comum operativa já dada" (Luhmann; 1996a, p. 56).

Toda observação necessita da indicação do que se observa, quer dizer, necessita de uma estratégia diferenciadora que distinga uma unidade em duas formas: sistema (que observa) e entorno (observado). Toda forma é uma linha fronteiriça, contingente, " $a$ qual, no entanto, só é válida relativamente ao observador, podendo ser traçada, de modo diferente, por qualquer outro observador" (Luhmann, 1997, p. 37). A forma é, nesse sentido, uma diferença e exige a exposição da parte indicada quando se quer proceder a novas operações (Luhmann; 1996a). Ao indicar uma parte da forma, automaticamente a outra é identificada, e essa operação é autorreferencial ao já pressupor uma parte que fez a observação. Essa observação feita operou com a estrutura que lhe é característica, ou seja, com critérios, motivos, valores, que lhe identificam ao indicarem a diferença. Sem observador que restrinja as possibilidades reais ilimitadas, não haveria identidade e, portanto, diferença.

O problema da dupla contingência, acima mencionado, já abordava esse desafio teórico, e a restrição/identificação das formas era alcançada na medida em que ALTER e EGO agiam em relação às expectativas recíprocas, e, em decorrência delas, poder-se-ia chegar à superação da letargia comunicativa, construindo uma rede de ações recíprocas concatenadas. Isso pode levar à formação de sistema, diferenciado e identificado com distintas operações de indicação e seleção. A partir dessas premissas, Luhmann elabora seu conceito de sistema social, que permeará todas as análises subsequentes da sociedade. A distinção sistema/entorno sugere que o sistema é a parte da qual saem distinções, indicações e seleções ${ }^{1}$, é o "ponto de

[1] Com o conceito de forma, Luhmann acredita encontrar um conceito de grande generalidade, sendo aplicado na matemática, na semiologia, na sociologia. Com essa perspectiva, também busca superar distinções entre disciplinas formais e humanas, acreditando em uma síntese teórica. Tal 
Arquimedes" para o observador. "Indicando", o sistema seleciona dimensões que, de outra forma, seriam intangíveis e, assim, diminui a complexidade com base em seus próprios processos constitutivos, que ademais estruturam sua própria observação. Assim, mesmo a causa é uma construção interna do sistema, reconfigurada e traduzida internamente, de acordo com sua estrutura subjacente' ${ }^{1}$. Nesse sentido, algo só pode ser entendido como causa se o próprio sistema assim o percebe: aqui ocorre a transformação de ruído ambiental em informação sistêmica.

O sistema opera sempre reduzindo possibilidades, selecionando ruídos do entorno, dotando-os de sentido ao incorporá-los aos seus processos internos (Nafarrate, 1993). A questão do sentido se relaciona à complexidade intransponível (e inesgotável) que circunda os sistemas, que fornece, portanto, um horizonte de possibilidades que colocam o sistema sempre se deparando com outras formas de vivência e ação. Logo, a complexidade observada nas alternativas (contingência absoluta) envolve um processo de seleção inevitável que "forma parte da consciência do sentido e da comunicação nos sistemas sociais" (Luhmann, 1998, p. 78). Isso tem consequências também para a formação dos sistemas, pois "o entorno se dá na forma de sentido e os limites do entorno são limites de sentido" (Luhmann, 1998, p. 79).

Todo sistema é, então, reprodutor de sentido, âmbito que transforma ruídos externos ou internos em informações dotadas de sentido. Decorre desse processo que o sistema aumenta sua própria complexidade interna, tendo que reagir, por sua vez, a ela (Araújo; Waizbort, 1999). Nesse caso, o sentido global é reintroduzido em formas, subsistemas, que adquirem autonomia relativa ao sistema do

conceito de forma é, também, para Luhmann, a possibilidade teórica da busca por "algum tipo de formas duradouras" (Luhmann, 1997, p. 37) que possam se localizar além do construtivismo radical e da autorrelativização que tomaram as teorias sociais no fim do século passado.

[1] Os sistemas na modernidade vão desenvolver formas específicas para observar o mundo em função de suas estruturas também específicas. A política tende a observar a sociedade em função do código poder/não poder, a ciência verdade/ não verdade a economia ter/ não ter, e assim, Luhmann sustentará em outro patamar o conceito parsoniano de meios de comunicação simbolicamente generalizados, como o poder, a verdade e a propriedade. 
qual se diferenciou. A reprodução do sistema cria e cristaliza expectativas de seleção que se vinculam ao sentido específico do sistema correspondente, reduzindo, de forma intermediária, as possibilidades de orientação que estão disponíveis. $\mathrm{Na}$ teoria dos sistemas sociais, encontrar-se-ão "principalmente expectativas de comportamento" diferenciadas (Luhmann, 1998, p. 107), estas estruturam o processamento do sistema e, portanto, tem existência para além do tempo imediato.

$\mathrm{Na}$ formação de estruturas por meio de expectativas, o processo de redução de complexidade (das possibilidades de ação) por meio de seleções direciona o sistema para a sua autorreprodução. $\mathrm{O}$ que é possível caso a caso inscreve-se nas disposições estruturais anteriormente selecionadas, isso dota o sistema de uma fluidez de elementos estruturada para a sua autopoiésis. Assim, o sistema autopoiético apresentará uma unidade macroestrutural, que, no nível de sua reprodução total, aparecerá como função (Luhmann, 1998). A penetração em âmbitos subsistêmicos apresentará a estrutura funcional desdobrada em distintos níveis, e, mesmo com essa diferenciação, a unidade e a identidade em torno de uma função específica permanece. As empresas reproduzem, no fenômeno econômico, o código global ter/não. Diferenciações, quaisquer que sejam, reproduzem o código estrutural, de outra maneira não poderiam pertencer no sistema ao qual correspondem. Fala-se, assim, em autorreferencialidade sistêmica, em operações que se orientam cegamente, como se o que estivesse fora do alcance estrutural de sentido não pudesse ser observado, a menos que fosse incorporado à cadeia de autoprodução. A esse fenômeno dá-se o nome de "fechamento operacional".

"No plano das operações próprias do sistema não há nenhum contato com o entorno. Isto vale ainda quando $-e$ sobre este dificil princípio, que contradiz toda a tradição da teoria do conhecimento, devemos chamar expressamente a atenção - estas operações são observações ou operações cuja autopoiésis produz uma auto-observação. Tampouco 
para os sistemas que observam existe, no plano de seu operar, nenhum contato com o entorno" (Luhmann; De Georgi, 1993, p. 49).

Para a teoria econômica, o fechamento operacional da economia torna-se claro a partir do momento em que se abstraem, de motivos morais e sentimentais dos participantes, as transações econômicas, "os motivos dos envolvidos puderam-se uniformizar e referir a utilidades calculáveis. (...) o que decide é o ganho ou a perda" (Luhmann, 2007, p. 770). Também a economia doméstica volta-se cada vez mais para o mercado, e a totalidade de sua produção passa a se localizar no mercado e em função dele, monetarizando-se devido ao caráter sistêmico do mesmo. Com isso, as referências econômicas passam a se basear não mais em fenômenos naturais, mágicos ou tradicionais, e se localizam basicamente nas relações entre "indivíduos-que-atuam-racionalmente". Em tal sistema, tudo se observa com o código binário ter/ não ter, e toda a comunicação é remetida a este.

Toda a fenomenologia do sistema acontece de forma contingente e contextual, quer dizer, em outro contexto, poder-se-iam esperar outros fenômenos, levando-se em conta um histórico de comunicações próprio, decorrente da relação sistema/entorno; mas isso não necessariamente decorre em adaptação já que o entorno é sempre mais complexo. A essa maneira específica de relação dá-se o nome de "acoplamento estrutural" (Maturana, 1983; Luhmann; 1998). Tal fenômeno não determina o que sucede no sistema, mas pode "irritar" o processo reprodutivo de modo a ser incorporado como elemento inovador em sua rede de processos autopoiéticos. Ainda acoplada ao entorno, a reprodução do sistema consiste na reprodução de sua estrutura binária básica, que a todo o momento é irritada pelo entorno, cabendo ao sistema incorporar isso como inovação ou ignorar os ruídos. Quando é indiferente, resta ao sistema o ônus de não acompanhar as transformações do entorno que a todo o momento acontecem. A economia reage a ruídos da cultura, da polí- 
tica, da tecnologia, seguindo caminhos evolutivos que se objetivam em função de sua estrutura e de como esta absorve tais ruídos.

O contraste informacional com seu ambiente é condição sob a qual o sistema opera e para a qual só existe uma saída: a redução da diferença, da complexidade, através de seus próprios processos. Essa condição envolve outros sistemas funcionais que constantemente se encontram em intercâmbio informacional entre si, através de sucessivos acoplamentos estruturais, fazendo com que a rede de informações que se estrutura no interior do sistema inclua informações novas de acordo com seu operar característico, sua autopoiésis. Essas relações podem estar relacionadas a "contribuições" recíprocas entre sistema, o que envolve exigências de funções mútuas na medida em que as funções são fragmentadas na modernidade.

"Além da sociedade, todo sistema parcial pode observar outros sistemas parciais. Em tal caso, fala-se de contribuição. Apesar de que se refira primariamente às exigências de funções nas relações da sociedade, todo sistema parcial deve também ter em conta as contribuições nas relações de outros sistemas parciais: por exemplo, no sistema político existem leis para a economia, no sistema econômico se subsidia a investigação científica, no sistema educativo se forma para o trabalho. Isto significa que, com base na sua inalienável autonomia recíproca, os sistemas de funções também são estritamente interdependentes. As interdependências têm um significado diferente segundo o sistema: por exemplo, o sistema educativo observa o sistema político de maneira diferente que o sistema jurídico, e para o sistema político esta diferença de perspectiva é uma diferenciação do entorno, que não se encontra no entorno do sistema educativo ou do sistema jurídico" (Baraldi, 1996, p. 62).

Assim, por meio de acoplamentos estruturais entre sistemas autônomos, a sociedade evolui e assume formas específicas. Pode- 
se observar o acoplamento estrutural entre sistema econômico e político nos impostos, já que aí está explícita uma medida política executada mediante pagamentos econômicos. De um lado, decide-se no sistema político por meio do poder e, por outro, efetua-se no sistema econômico por meio do dinheiro, com consequências evidentes tanto para a política - protestos por altos impostos - quanto para a economia - descapitalização. Pode-se observar também o acoplamento estrutural entre economia e direito na forma da propriedade e do contrato. Essa forma assumida pela propriedade, agora com garantias jurídicas extraterritoriais, fez possível a enorme expansão da economia pela inclusão de sócios desconhecidos e não pertencentes à mesma comunidade (Luhmann, 2007). Esse acoplamento vai determinar a direção da mudança sistêmica em ambos os sistemas acoplados, que terão necessariamente que responder constantemente e individualmente a essas mudanças. A economia global exige um sistema de direito internacional integrado ao mesmo tempo em que exige atuação política global em função da desterritorialização dos processos econômicos, com criação de mecanismos de controle de fluxo de capitais internacionais.

Esse requinte relacional acima descrito envolve, então, fechamento operacional com abertura ambiental: o sistema se fecha pela reprodução de seu processo funcional ao mesmo tempo em que, com base nele, observa e aproveita o entorno em suas operações. Nesse sentido, pelo contato coevolutivo com o entorno, o sistema segue uma direção determinada, tolerada pelo ambiente. Essa direção está ligada fundamentalmente aos ruídos externos, que são incorporados ao sistema via acoplamento estrutural, reafirmando que tal perturbação é uma construção própria do sistema e só é entendida enquanto tal quando, pelas operações anteriores, é absorvida pela rede de comunicações autopoiéticas que são dotadas de sentido no próprio sistema, o que envolve "seleção".

Tem-se dito que o sistema constrói internamente sua própria maneira de operar, que esta cria os limites que o distingue de seu ambiente, mas como o faz? Atentar para as seleções internas pode 
ser uma saída, mas ainda se fica preso a outra pergunta: como se seleciona? A solução de Luhmann é recorrer ao processo fundamental de constituição dos sistemas sociais, ou seja, as comunicações ${ }^{1}$. Existe imenso número de possibilidades de comunicação que tornam a interação cotidiana, por exemplo, algo totalmente improvável (Luhmann; 2001), sujeita a ruídos de toda a espécie, os quais dificultam a consecução dos pré-requisitos para que aja a compreensão entre EGO e ALTER. A saída do sistema da sociedade foi estruturar sua reprodução, com base na comunicação, em códigos binários que reduzem as possibilidades de comunicação mal sucedida, referenciando-as a uma forma de dois lados: sim e não. Há uma diferenciação dos acontecimentos, desta vez, em codificados e não codificados: os primeiros "atuam em um processo comunicativo como informação, os não codificados como interrupção" (Luhmann, 1998, p. 144). Os códigos combinam, então, fechamento operacional com abertura ambiental, dotando de significado as informações incorporadas à autopoiésis do sistema, que opera, então, incessantemente com a fundamental diferença entre sistema e entorno.

A diferenciação da sociedade basicamente se refere a esta característica dos sistemas sociais, ou subsistemas: fechamento operacional pelo sentido dotado pelo código às informações do entorno. Assim, nenhum sistema social é igual ao outro no que se refere ao sentido de suas operações, já que a diferenciação da moderna sociedade desemboca no controle de códigos específicos por sistemas sociais distintos. É o caso do direito e o código legal/ ilegal, da política e o código poder/não poder, da economia e o código ter/ não ter, da ciência e o código verdadeiro/ não verdadeiro. A valoração de determinado lado do código leva a cristalização de meios comunicativos que asseguram a continuação da autopoiésis, condicionando, assim, o êxito da comunicação. Esses meios comunicativos são os simbo-

[1] Luhmann refere-se à comunicação como processo fundamental do sistema, como os seus unitact. "Um sistema social surge quando a comunicação desenvolve mais comunicação, a partir da mesma comunicação" (Luhmann; 1996a, p. 68). É, então, o processo fundamental sobre o qual o sistema se reproduz, com base em suas próprias informações anteriores: não existe sistema social que não tenha como operação própria a comunicação, e não existe comunicação fora dos sistemas sociais. 
licamente generalizados, a verdade, o dinheiro, o poder, o amor, os valores, entre outros (Luhmann, 2001). Tais meios operam reduzindo complexidade e cristalizando expectativas de êxito comunicativo.

Operativamente fechados, reproduzindo seus próprios processos, sistemas sociais, como a economia, funcionam preservando sua própria estrutura de expectativas ao mesmo tempo em que observam seu entorno em constante evolução. Não havendo intercâmbio de sentido, já que cada sistema imprime sobre as informações de outros seu próprio código - a economia com o código ter/ não ter -, os sistemas sociais operam somente com seu universo de expectativas pré-estruturado, com base no passado de comunicações, e com sua estrutura acoplada estruturalmente a outros sistemas. Como consequência, a sociedade moderna caracteriza-se por vários centros funcionais, cada qual executando a função que lhe estrutura. A economia funciona reproduzindo o ganho em um contexto em que as fundamentações que lhe são alheias operam como fator destrutivo, conquanto não sejam incorporadas à cadeia de reprodução autopoiética do próprio sistema. Isso se verifica nas pressões políticas, nas mudanças tecnológicas ${ }^{1}$ e na diferenciação do sistema do direito. Todas essas fontes de irritação se apresentam como complexidade não estruturada do entorno, cabendo ao sistema econômico respostas com base em sua própria estrutura de expectativas.

Evidencia-se, portanto, que o fechamento operacional do sistema não necessariamente exige equilíbrio e adaptação, já que o entorno é sempre mais complexo. Não haverá uma simetria processual "ponto a ponto" entre a economia e os outros sistemas de seu entorno, e sempre se terá que lidar com transformações do entorno, já que este não é controlável do ponto de vista do próprio sistema econômico. Isso só reafirma a ideia de que a economia, funcionando como sistema social, insere-se na sociedade como diferença no processo social total, portanto sua reprodução é condicionada também

[1] A teoria evolucionária se assemelha, em muitos aspectos, à teoria sistêmica, conquanto se perceba que Luhmann não trata a mudança econômica em termos de transformações tecnológicas somente, embora estas possam ser percebidas pelo sistema como uma pressão, e este reaja, alterandose. Sobre a teoria evolucionária, ver Nelson; Winter (2005). 
pela forma como a sociedade se manifesta, em diferentes contextos e tempos. Não se pode, para fins analíticos, abstrair os processos econômicos, isolando-os de todo resto, já que este existe em uma base social operativa já dada. Nesse sentido, a mudança econômica surge como mudança autoproduzida em função dos dois lados da forma, sistema e entorno, não sendo nem a manifestação de intercâmbio de sentido desde fora, nem um solipsismo desde dentro. Mudança é, enfim, a "diferenciação da diferença".

\section{CONCLUSÃO}

O debate recente entre a economia e a sociologia econômica tem possibilitado a vários campos do conhecimento a oportunidade de se comunicarem mais intensamente, com ganhos para todos os lados. A pretensa visão dos economistas de pensar sua ciência como uma forma de conhecimento emancipada das outras esferas da vida social, cujos pressupostos estão alicerçados em algum mecanismo geral e abstrato, tem, em consequência, perdido cada vez mais espaço nas Ciências Sociais.

A respeito dessa discussão, a teoria dos sistemas pode ser considerada como uma tentativa para pensar a relação entre indivíduo e sociedade, bem como para pensar as diversas esferas sociais. Para tanto, articula conceitos como ação e estrutura, buscando entender não somente estas, mas também motivação e interesse no interior dos sistemas sociais. Nesse sentido, a sociedade vai aparecer como resultado das relações entre sistemas não exatamente imbricados, mas acoplados desde as suas próprias estruturas. Pode-se dizer que as diversas formulações desta teoria buscaram dar conta de um problema comum tanto à sociologia quanto à economia, o de subsumir o econômico no social e vice-versa. Pensando esse problema, o presente trabalho enfocou duas perspectivas centrais nas formulações sistêmicas, que ajudam a pensar o lugar do econômico e do social dentro da teorização social. 
A primeira perspectiva é a de Talcott Parsons. Este advoga a abertura nos sistemas sociais, entre os quais, há intercâmbio informacional, incluídas as dimensões social e econômica. Isso quer dizer que, a despeito do que foi comumente aceito, o autor não defende uma divisão do trabalho entre sociologia e economia, mas, ao pressupor o intercâmbio simbólico entre os sistemas, vai admitir que há um condicionamento mútuo entre eles. Nesse sentido, as transformações econômicas são transformações internas, como resultado de processos externos não econômicos. Com isso, a sociedade seria um processo ininterrupto de adaptações dos sistemas sociais ao seu ambiente.

Já Niklas Luhmann nega a possibilidade de intercâmbio informacional entre sistemas sociais, e, portanto, nega também a adaptação às condições ambientais. Qualquer mudança nas condições internas dos sistemas são mudanças processadas internamente pelo sentido característico nele processado. Assim, transformações do entorno são sempre observadas desde o ponto de vista do sistema e serão incorporadas desde o sentido que o sistema lhes atribui. Isso quer dizer que fatores externos são sempre elementos de irritação, mas podem servir como elemento de mudança se assim o sistema o incorporar. Esse é o caso da mudança econômica, por exemplo, que é processada pelo sistema, mas sempre em função das alterações a que a sociedade como um todo passa em seu intercurso evolutivo.

Finalmente, em termos macroestruturais, que geralmente é a dimensão da teorização a que se faz menção quando se discute o papel do social na economia, a teoria dos sistemas poderia ser um importante referencial formal e substantivo para a economia e a sociologia, como disciplinas acadêmicas, avançarem no entendimento dessas duas dimensões. Portanto, advoga-se aqui por um tratamento simétrico dessas instâncias. 


\section{REFERÊNCIAS}

ABRAMOVAY, Ricardo. Entre Deus e o Diabo: mercado e interação humana nas ciências sociais. Tempo Social - Revista de Sociologia da USP. Vol. 16, n², Novembro de 2004.

ARAÚJO, Cicero. \& WAIZBORT, Leopoldo. "Sistema e evolução na teoria de Luhmann". Lua nova, nº. 47, 1999.

BARALDI, Claudio. Diferenciación de la sociedad. In: CORSI, Giancarlo et. Al. Glossário sobre la teoría social de Niklas Luhmann. México D. F.: Antrhopos, 1996.

BARBER, Bernard. All Economies are "Embedded": the career of a concept, and beyond. Social Research, Summer, Vol. 6, n 2, p. 387413, 1995.

BERTALANFFY, Ludwig V. Teoria geral dos sistemas. Petrópolis: Vozes, 1973.

BOETTKE, P.; STORR, V. H. Post-classical political economy: polity, society and economy in Weber, Mises and Hayek: Austrian School perspectives: Max Weber, Ludwing Von Mises, Fiedrich A. Von Hayek. The American Journal of Economics and Sociology, New York, Vol. 61, n. 1, pp. 161-191, jan. 2002.

CARLOS GRAÇA, João. Finalmente, o que é mesmo a Nova Sociologia Económica? Actas dos ateliers do V Congresso da Associação Portuguesa de Sociologia. Sociedades Contemporâneas: Reflexividade e Acção. Teorias e Metodologias de Investigação, 2004.

DALZIEL, Paul; HIGGINS, Jane. Pareto, Parsons, and the Boundary between Economics and Sociology. American Journal of Economics and Sociology, Vol. 65, n. 1, 2006.

DESAI, Meghnad. Economia Neoclássica. In: OUTHWAITE, William \& BOTTOMORE, Tom. (Orgs.). Dicionário do Pensamento Social do Século XX. Rio de Janeiro:Jorge Zahar Editor, 1996. 
GOMEZ FONSECA, Miguel A. Reflexiones Sobre el Concepto de "Embeddedness". Polis, 04, Vol. 2, pp. 145-164, 2004.

GRANOVETTER, Mark. Economic Action in Social Structure: a theory of embeddedness, American Jounal of Sociology, n. 91, pp. 481-510, 1985.

GUEDES, Sebastião R. Observações Sobre a Economia Institucional: há possibilidade de convergência entre o velho e o novo institucionalismo? Anais do V Encontro Nacional de Economia Politica. Fortaleza (CE). (CD-Rom), 2000.

HODGSON, Geoffrey M. Economics and Institutions: a manifest for a modern institutional economics. Philadelphia: University of Pensylvania Press, 1988.

KAUFMANN, Felix. Metodologia das Ciências Sociais. Rio de Janeiro: Francisco Alves, 1977.

LUHMANN, Niklas \& DE GEORGI, Raffaele. Teoria de la sociedad. Guadalajara: Universidad de Guadalajara, 1993.

LUHMANN, Niklas. Introducción a la Teoría de los Sistemas. Universidade Iberoamericana, A. C, 1996.

La sociedad de la sociedad. México: Iberoamericana/ Herder, 2007.

. A improbabilidade da comunicação. Lisboa: Veja, 2001.

. Por que uma "teoria dos sistemas"?. In: NEVES, Clarissa E. B. \& SAMIOS, eva, M. B. Niklas Luhmann: A nova teoria dos sistemas. Porto Alegre: Ed. UFRGS/Goethe-Institut, 1997.

Sistemas sociales: lineamientos para una teoria general. Barcelona: anthropos; México: Universidade Iberoamericana; Santafé de Bogotá: CEJA, 1998. 
MATURANA, Humberto. “O que é ver?” In: MAGRO, Cristina; GRACIANO, Miriam; VAZ, Nelson. A ontologia da realidade. Belo Horizonte: Ed. UFMG, 1983.

MÜNCH, Richard. A teoria parsoniana hoje: a busca de uma nova síntese. In: GIDDENS, Anthony; TURNER, Jonathan. Teoria social hoje. São Paulo: UNESP, 1999.

NAFARRATE, Javier Torres. "Nota a la versión en español”. In: LUHMANN, Niklas \& DE GEORGI, Raffaele. Teoria de la sociedad. Guadalajara: Universidad de Guadalajara, 1993.

NELSON, Richard R.; WINTER, Sidney G. Uma teoria evolucionária da mudança econômica. Campinas: Editora da UNICAMP, 2005.

NEVES, Clarissa E. B. e NEVES, Fabrício M. O que há de complexo no mundo complexo. Sociologias. Porto Alegre, Vol. 1, n. 1, 2006.

PARSONS, Talcott. "O conceito de sistema social”. In: CARDOSO, F. H. \& IANNI, O. Homem e sociedade. São Paulo: Companhia Editora Nacional, 1976.

O sistema das sociedades modernas. São Paulo: Pioneira: 1974.

The social system. Toronto: Free Press, 1951.

. The structure of social action. Toronto, Ontario: Cullier / Macmillan, 1966.

PARSONS, Talcott; SHILS, Edward (Eds.). Toward a general theory of action. New York: Harper \& Row, 1951.

ROBBINS, Lionel. An Essay on The Nature and Significance of Economic Science. Second edition, revised and Extended. Macmillan And Co., Limited St. Martin's Street, London, 1945.

SAMUELS, Warren J. The Present State of Institutional Economics. Cambridge Journal of Economics, n. 19, pp. 569-590, 1995. 
SOROKIN, Pititim A. Novas teorias sociológicas. Porto Alegre: Editora Globo; São Paulo: EDUSP, 1969.

SWEDBERG, Richard. The New 'Battle of Methods'. Challenge, jan/feb, 33, no1, pp. 33-38, 1990. Max Weber e a Idéia de Sociologia Econômica. Editora UFRJ/Beca Produções Culturais. Coleção Economia e Sociedade. Rio de Janeiro e São Paulo, 2005. Institutional Economics: surveying the 'old and the 'new'. Metroeconomica, Vol. 44, no. 1, fev, 1993.

VELTHUIS, Olav. The Changing Relationship Between Economic Sociology and Institutional Economics: From Talcott Parsons to Mark Granovetter. The American Journal of Economics and Sociology, October, Vol. 58, n4, pp.629, 1999.

WHALEN, Charles J. John R. Common's Institutional Economics: A ReExamination. Journal of Economic Issues. Lincoln: Jun, Vol. 23, nº. 2; pp. 443, 1989.

Recebido em: 27/04/2012

Aprovado em: 30/05/2012 